\title{
In vitro effects of oxpentifylline on inflammatory cytokine release in patients with inflammatory bowel disease
}

J M Reimund, S Dumont, C D Muller, J S Kenney, M Kedinger, R Baumann, P Poindron, B Duclos
Service

d'Hépatogastro-

entérologie et

d'Assistance Nutritive, CHRU Hautepierre, 67098 Strasbourg

Cedex, France

J M Reimund

R Baumann

B Duclos

Département

d'Immunologie,

Immuno-

pharmacologie et

Pathologie, Centre de

Recherches

Pharmaceutiques,

67401 Illkirch

Graffenstaden, France

J M Reimund

$S$ Dumont

$P$ Poindron

Unité de Recherche

INSERM U 381,

Avenue Molière, 67000

Strasbourg Cedex,

France

J M Reimund

$M$ Kedinger

B Duclos

Laboratoire de

Biophysique, U.R.A.

n 491 du CNRS, Centre

de Recherches

Pharmaceutiques,

67401 Illkirch

Graffenstaden, France

C D Muller

J S Kenney

Correspondence to:

Dr Jean Marie Reimund,

Département

d'Immunologie,

Immunopharmacologie et

Pathologie, Centre de

Recherches

Pharmaceutiques, 74 Route

du Rhin, 67401 Illkirch

Graffenstaden, France.

Accepted for publication

20 December 1996

\begin{abstract}
Background-Inflammatory cytokines, including tumour necrosis factor- $\alpha$ (TNF- $\alpha$ ) and interleukin (IL)-1ß, have been implicated as primary mediators of intestinal inflammation in inflammatory bowel disease.

Aim-To investigate the in vitro effects of oxpentifylline (pentoxifylline; PTX; a phosphodiesterase inhibitor) on inflammatory cytokine production (1) by peripheral mononuclear cells (PBMCs) and (2) by inflamed intestinal mucosa cultures from patients with Crohn's disease and patients with ulcerative colitis.
\end{abstract}

Methods-PBMCs and mucosal biopsy specimens were cultured for 24 hours in the absence or presence of PTX (up to 100 $\mu \mathrm{g} / \mathrm{ml}$ ), and the secretion of TNF- $\alpha$, IL$1 \beta, I L-6$, and IL-8 determined by enzyme linked immunosorbent assays (ELISAs). Results-PTX inhibited the release of TNF- $\alpha$ by PBMCs from patients with inflammatory bowel disease and the se-

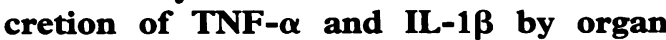
cultures of inflamed mucosa from the same patients. Secretion of TNF- $\alpha$ by PBMCs was inhibited by about $50 \%$ at a PTX concentration of $25 \mu \mathrm{g} / \mathrm{ml}\left(\mathrm{IC}_{50}\right)$. PTX was equally potent in cultures from controls, patients with Crohn's disease, and those with ulcerative colitis. The concentrations of IL-6 and IL-8 were not significantly modified in PBMCs, but IL-6 increased slightly in organ culture supernatants.

Conclusions-PTX or more potent related compounds may represent a new family of cytokine inhibitors, potentially interesting for treatment of inflammatory bowel disease.

(Gut 1997; 40: 475-480)

Keywords: inflammatory bowel disease, inflammatory cytokines, oxpentifylline, cyclic nucleotide phosphodiesterase inhibitors.

Inflammatory cytokines - tumour necrosis factor- $\alpha$ (TNF- $\alpha)$, interleukin-1 $\beta$ (IL-1 $\beta$ ) and interleukin-6 (IL-6) - and neutrophil activating peptide-I/interleukin-8 (IL-8) have been shown to be important mediators during the development and perpetuation of intestinal inflammation in inflammatory bowel diseases. Raised concentrations of TNF- $\alpha$ in serum, as well as raised faecal concentrations ${ }^{2}$ and increased TNF- $\alpha$ production by peripheral blood mononuclear cells (PBMCs), ${ }^{3}$ lamina propria mononuclear cells (LPMCs), ${ }^{45}$ and organ cultures of biopsy specimens from inflamed ${ }^{5}$ or morphologically normal inflammatory bowel disease intestinal mucosa ${ }^{6}$ have been reported. Similarly high expressions of IL- $1 \beta,{ }^{3-7}$ IL- $6,{ }^{89}$ and IL- $8,{ }^{10}$ have been found in both Crohn's disease and ulcerative colitis. Neutralisation of TNF- $\alpha$ by anti-TNF- $\alpha$ antibodies has recently been suggested to be of therapeutic benefit in Crohn's disease by both open $^{11} 12$ and controlled therapeutic trials. ${ }^{13}$ Therefore cytokine inhibition seems a rational target in treatment of inflammatory bowel disease.

Numerous points of therapeutic intervention to inhibit the synthesis or the action of cytokines are possible. ${ }^{14}$ Among them, modulation of cytokine transcription by oxpentifylline (pentoxifylline; PTX), a phosphodiesterase (PDE) inhibitor, has been explored. ${ }^{15}{ }^{16}$ Inhibitors of PDE generate high intracellular cAMP concentrations, which are known to inhibit expression of TNF- $\alpha .{ }^{15} 16$ PTX, the 1-5oxohexyl analogue of the methylxanthine theobromine, was initially characterised as a haemorrheological agent and has been used in vascular disorders for the past 20 years. PTX has well known pharmacokinetics with minimal side effects.

The present work was designed to evaluate whether PTX reduces the spontaneous and stimulated production of TNF- $\alpha$, IL- $1 \beta$, IL- 6 , and IL-8 by PBMCs and organ cultures of colon biopsy specimens in patients with inflammatory bowel disease.

\section{Methods}

\section{PATIENTS}

A total of 27 patients (Crohn's disease: $n=18$; ulcerative colitis: $n=9$ ) were included in this study. They were prospectively included when entering our gastroenterology unit. Diagnosis was established according to the criteria of Lennard-Jones. ${ }^{17}$ The Table shows the clinical data and treatments at the time of inclusion. In Crohn's disease, activity was assessed according to Van Hees et $a l,{ }^{18}$ and in ulcerative colitis by the criteria of Truelove and Witts. ${ }^{19}$ No patient had associated disease or was complaining of extraintestinal manifestations of inflammatory bowel disease or extraintestinal 
Clinical characteristics and treatment at the time of inclusion of the patients with Crohn's disease (CD) or ulcerative colitis (UC)

\begin{tabular}{|c|c|c|}
\hline & $\begin{array}{l}\text { Patients with } C D \\
(n=18)\end{array}$ & $\begin{array}{l}\text { Patients with UC } \\
(n=9)\end{array}$ \\
\hline Age (mean (range)) & $31(21-57)$ & $38(23-66)$ \\
\hline Sex (men/women) & $8 / 10$ & $5 / 4$ \\
\hline \multicolumn{3}{|l|}{ Disease activity (n): } \\
\hline Severe & 8 & 3 \\
\hline Moderate & 8 & 6 \\
\hline Mild & 2 & 0 \\
\hline \multicolumn{3}{|l|}{ Bowel involvement $(n)$ : } \\
\hline Ileum alone & 3 & - \\
\hline Colon alone & 7 & - \\
\hline Ileocolonic disease & 8 & - \\
\hline Whole colon & - & 6 \\
\hline Left colon & - & 3 \\
\hline \multicolumn{3}{|l|}{ Current treatment: } \\
\hline Steroids $>10 \mathrm{mg} /$ day & 8 & 3 \\
\hline 5-Aminosalicylic acid & 5 & 2 \\
\hline Both & - & 4 \\
\hline No medication & 5 & - \\
\hline
\end{tabular}

Disease activity was assessed by the index of Van Hees et al ${ }^{18}$ for patients with $\mathrm{CD}$ and by the criteria of Truelove and Witts ${ }^{19}$ for patients with UC.

infection. Serological studies for Yersinia enterocolitica and cytomegalovirus, and stool cultures including search for Clostridium difficile were negative in all cases. Peripheral blood was taken and biopsies were performed in fasting patients free of medication for at least 12 hours.

PERIPHERAL BLOOD MONONUCLEAR CELLS In 14 patients (Crohn's disease: $n=10$; ulcerative colitis: $n=4$ ) and in six healthy subjects (control group) PBMCs were separated as previously described by Bøyum. ${ }^{20}$ Briefly, peripheral blood diluted with $\mathrm{Ca}^{2+}$ and $\mathrm{Mg}^{2+}$ free (CMF) Hank's balanced salt solution (HBSS; Gibco BRL, Cergy, France) containing 100 IU heparin/ml was layered over Ficoll Hypaque (Pharmacia AB, Uppsala, Sweden) and centrifuged for 40 minutes at $400 \mathrm{~g}$. Cells harvested from the interface were washed three times in HBSS-CMF and resuspended at a final concentration of $2 \times 10^{6} / \mathrm{ml}$ in a culture medium consisting of RPMI 1640 (Gibco) supplemented by $10 \%$ heat inactivated foetal calf serum (FCS, Gibco), 2mM L-glutamine (Gibco), penicillin (100 IU/ml), and streptomycin $(100 \mu \mathrm{g} / \mathrm{ml})$ (Diamant, Paris, France). Human PBMCs were incubated with doses of PTX (Sigma, Paris, France) ranging from 1 $\mu \mathrm{g} / \mathrm{ml}$ to $100 \mu \mathrm{g} / \mathrm{ml}$, with or without simultaneous activation by $1 \mu \mathrm{g} / \mathrm{ml}$ lipopolysaccharide from Salmonella abortus equi (LPS, Sigma) and $1 \mu \mathrm{g} / \mathrm{ml}$ of phytohaemagglutinin (PHA, Difco, Detroit, MI, USA) in 24 well culture plates (Falcon, PolyLabo, Strasbourg, France) for 24 hours at $37^{\circ} \mathrm{C}$ in a humidified $5 \% \mathrm{CO}_{2} / 95 \%$ air atmosphere. Supernatants were then removed, filtered, and stored at $-80^{\circ} \mathrm{C}$ until cytokine analysis. Cell viability was assessed by the trypan blue exclusion test.

INTESTINAL BIOPSY SPECIMENS FROM PATIENTS AND TISSUE CULTURE

In 17 patients with inflammatory bowel disease colon biopsy specimens were obtained during colonoscopy (Crohn's disease, $n=11$; ulcer- ative colitis, $n=6$ ) from macroscopically involved areas of intestinal mucosa (grades 3/4) according to Wardle et al. ${ }^{21}$ All patients required a colonoscopy for clinical reasons. In each patient eight biopsy specimens were taken. Two were fixed in formalin for histological assessment and six placed in HBSS-CMF supplemented with $100 \mathrm{IU} / \mathrm{ml}$ penicillin and $100 \mu \mathrm{g} / \mathrm{ml}$ streptomycin (Diamant) at $4^{\circ} \mathrm{C}$ for organ culture. After collection, the biopsy specimens were transferred to the laboratory. Within three hours after collection, the tissue was gently washed three times in CMF-Hank's medium with added penicillin and streptomycin, blotted carefully, weighed (range 3-12 $\mathrm{mg}$ ), and placed in 24 well tissue culture plates in $1 \mathrm{ml}$ culture medium with increasing concentrations of PTX ( 1 to $100 \mu \mathrm{g} / \mathrm{ml}$ ). After 24 hours of culture at $37^{\circ} \mathrm{C}$ in a humidified $95 \%$ air $/ 5 \% \quad \mathrm{CO}_{2}$ atmosphere, supernatants were removed, filtered, and stored at $-80^{\circ} \mathrm{C}$ until cytokine analysis.

Structural integrity of biopsy specimens was assessed by standard histology. Biopsy specimens from each patient were fixed in $10 \%$ buffered formalin and embedded in paraffin wax after dehydration, clearing, and impregnation. Serial $4 \mu \mathrm{m}$ sections were stained with haematoxylin and eosin. Lactate dehydrogenase release in supernatants of cultured tissues was also determined.

\section{IMMUNOASSAYS FOR CYTOKINES}

Culture supernatants were assayed with twosite enzyme linked immunosorbent assays (ELISAs) specific for human interleukins IL-1 $\beta$, IL-6, IL-8, and TNF- $\alpha$. Antibodies used were a gift from J Kenney, Antibody Solutions, Half Moon Bay, CA, USA. Quantitative evaluation of monocyte secreted interleukins was achieved by ELISAs using conditions described by Kenney et al, ${ }^{22}$ with slight modifications as described here. Tween (500 $\mu 1 / 1$ PBS) was substituted for thimerosal for the preparation of incubation, blocking, and washing buffers. Polyvinyl chloride plates (Costar, No 2596) were coated with $50 \mu \mathrm{l}$ per well of antibodies $(15 \mu \mathrm{g} / \mathrm{ml})$ and incubated overnight at $4^{\circ} \mathrm{C}$. After the usual wash and non-specific saturation steps, $25 \mu l$ standard or sample were added to $25 \mu$ l biotinylated monoclonal antibody $(2 \mu \mathrm{g} / \mathrm{ml})$ and incubated for two hours at room temperature. After washing steps, $50 \mu \mathrm{l}$ of a peroxidase-streptavidin dilution (1:3000 in PBS Triton) were added and the mixture incubated for one hour at room temperature. A colorimetric reaction (optical density at $450 \mathrm{~nm}$ ) using o-phenylenediamine dihydrochloride as peroxidase substrate was performed after four washing steps. Concentrations $(\mathrm{pg} / \mathrm{ml})$ of unknown samples were computed by interpolation with a standard curve run on each plate using four parameters logistics analysis.

STATISTICS

Data are expressed as means (SEM) of percentage of basal cytokine secretion. The 
symbol $\mathrm{n}$ refers to the number of experiments. ELISAs were performed on duplicate samples. Results were compared using Student's $t$ test for normally distributed data. For nonnormally distributed data, the Mann-Whitney U test, or the Kruskal Wallis test if more than two groups were compared, was used. The level of significance was taken as $\mathbf{p}<0 \cdot 05$.

\section{Results}

CELL AND TISSUE VIABILITY

Cell viability as assessed by the trypan blue exclusion test and structural integrity appreciated by standard histology was not affected by any drug concentration or LPS/PHA activation. Lactate dehydrogenase concentrations were significantly lower in organ culture supernatants than in the supernatants of uncultured biopsy specimens, indicating satisfactory tissue viability.
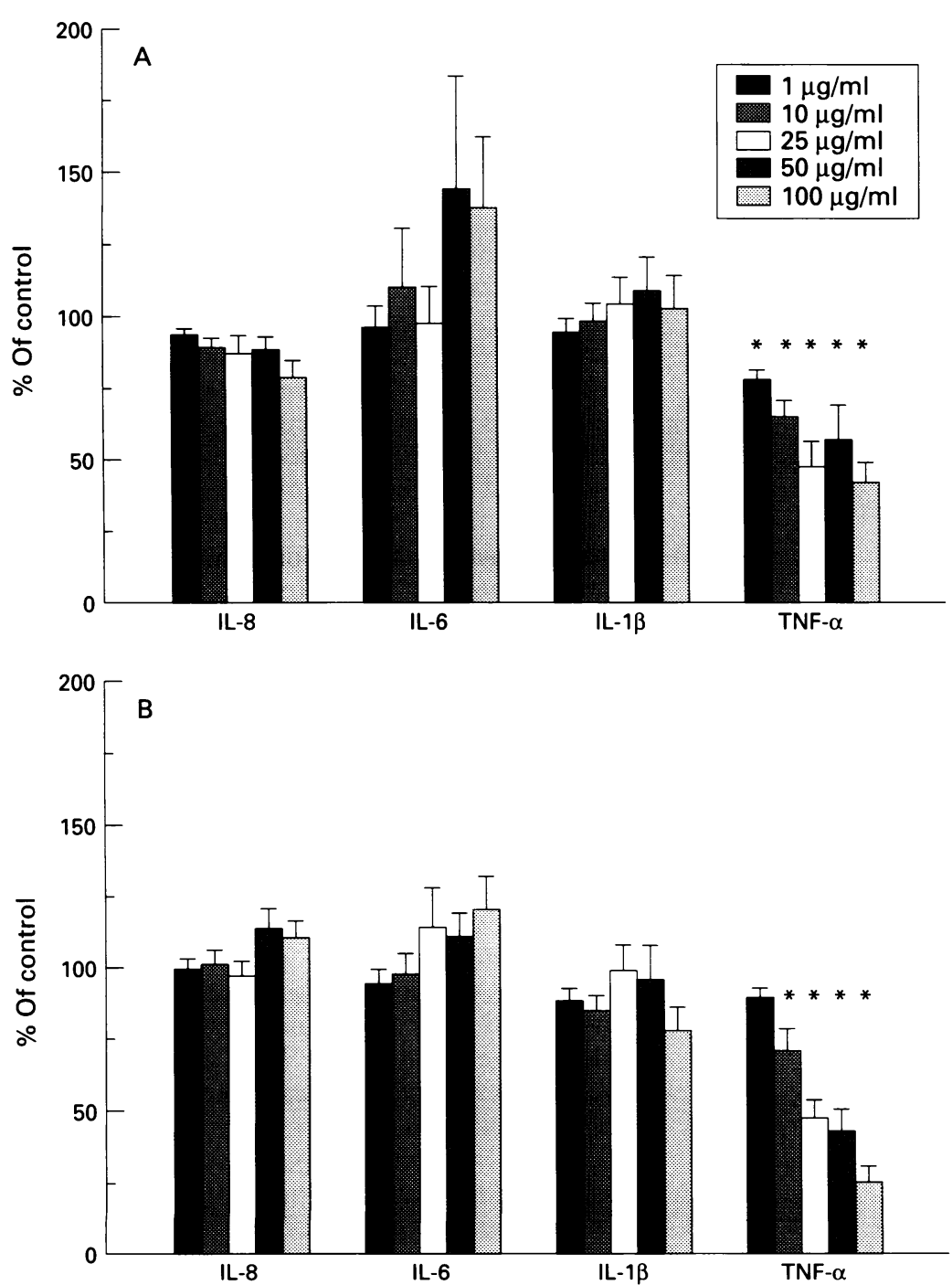

Figure 1: Effect of PTX on $I L-8, I L-6, I L-1 \beta$, and TNF- $\alpha$ release by PBMCs isolated from patients with inflammatory bowel disease. The effect of PTX $(1,10,25,50$, and 100 $\mu \mathrm{g} / \mathrm{ml}$ ) on cytokine production by PBMCs was evaluated by ELISA as described in Methods in the absence $(A)$ or presence $(B)$ of $1 \mu \mathrm{g} / \mathrm{ml} \mathrm{LPS} \mathrm{and} 1 \mu \mathrm{g} / \mathrm{ml}$ PHA. Results (mean (SEM), $n=14)$ express cytokine production as the percentage of control $(100 \%$ without activation by LPS/PHA: IL-8, 20.1 (3.8) $\mathrm{ng} / \mathrm{ml}, \mathrm{IL}-6,3 \cdot 8(0 \cdot 7) \mathrm{ng} / \mathrm{ml}, \mathrm{IL}-1 \beta$, $546 \cdot 1$ (181.5) pg/ml, TNF- $\alpha, 654.4(78.5) \mathrm{pg} / \mathrm{ml} ; 100 \%$ in presence of LPS/PHA: IL-8, 18.9 (3.1) $\mathrm{ng} / \mathrm{ml}, \mathrm{IL}-6,8 \cdot 1$ (2.4) $\mathrm{ng} / \mathrm{ml}, \mathrm{IL}-1 \beta, 1343 \cdot 8$ (398.4) $\mathrm{pg} / \mathrm{ml}, \mathrm{TNF}-\alpha, 1427 \cdot 2$ $\left.(375 \cdot 1) \mathrm{pg} / \mathrm{ml} ;{ }^{\star} p<0.001\right)$.
IN VITRO EFFECTS OF PTX ON SPONTANEOUS AND STIMULATED CYTOKINE PRODUCTION BY PBMCs

Spontaneous TNF- $\alpha$ and IL- $1 \beta$ production by PBMCs did not differ between cells obtained from controls, patients with Crohn's disease, or patients with ulcerative colitis $(\mathrm{p}<0.45$ and $\mathrm{p}<0.56$ respectively) in control plates without PTX. Despite a trend toward higher IL-1 $\beta$ and TNF- $\alpha$ production after activation by LPS/ PHA the difference did not reach significance (for example, for TNF- $\alpha$ : 891.6 (118.7) $v$ $1142.8(232.5) \quad v \quad 1995.9 \quad(164.7) \quad \mathrm{pg} / \mathrm{ml}$ respectively in controls, patients with Crohn's disease, and patients with ulcerative colitis). Stimulated IL-6 production and both spontaneous and stimulated IL-8 production by PBMCs were higher in patients with Crohn's disease or ulcerative colitis than in controls. This difference, however, was not significant. Neither disease activity, nor steroid or mesalazine treatment influenced the spontaneous or stimulated cytokine production by PBMCs.

When PTX was used, TNF- $\alpha$ concentrations in the supernatants of PBMCs from patients with inflammatory bowel disease were found to be significantly reduced after 24 hours of culture compared with basal production $\left(\mathrm{IC}_{50} \sim 25\right.$ $\mathrm{mg} / \mathrm{ml} ; \mathrm{p}<0.0001$ ) (Fig 1A). The effect of PTX on TNF- $\alpha$ production by PBMCs from patients with inflammatory bowel disease was the same in the absence or presence of activation by LPS/ PHA (Fig 1B) except for TNF- $\alpha$ at $100 \mu \mathrm{g} / \mathrm{ml}$ (43\% of the basal production without LPS/ PHA $v 26 \%$ with LPS/PHA; p<0.05). The pattern of the inhibition of PBMC TNF- $\alpha$ production by PTX in the presence or absence of simultaneous incubation with LPS/PHA did not differ between controls, patients with Crohn's disease, or patients with ulcerative colitis (Fig 2A and 2B).

PTX did not change the production of IL-1 $\beta$ by PBMCs from patients with inflammatory bowel disease either in the absence or presence of LPS/PHA $(p=0.86$ without activation by LPS/PHA and $p=0 \cdot 17$ with LPS/PHA; Fig $1 A$ and $1 B$ ). No difference was found between PBMCs from controls, patients with Crohn's disease or patients with ulcerative colitis (for example, $p=0.63$ for PTX $=100 \mu \mathrm{g} / \mathrm{ml}$ with LPS/PHA).

Despite a trend toward higher IL-6 secretion in the presence of PTX, this difference was not significant $(p=0 \cdot 29$; Fig $1 A)$. These results were not modified after LPS/PHA activation $(p=0 \cdot 10 ;$ Fig $1 B)$. Concentrations of IL-6 in the supernatants of PBMC cultures did not differ between controls, patients with Crohn's disease, and patients with ulcerative colitis.

Concentrations of IL-8 in the cell culture supernatant, in the presence or absence of activation by LPS/PHA (Fig 1A and 1B), were not modified by PTX in controls, patients with Crohn's disease, or patients with ulcerative colitis.

The effect of PTX upon cytokine production (particularly TNF- $\alpha$ production) did not differ according to disease activity, or steroid or mesalazine treatment (data not shown). 

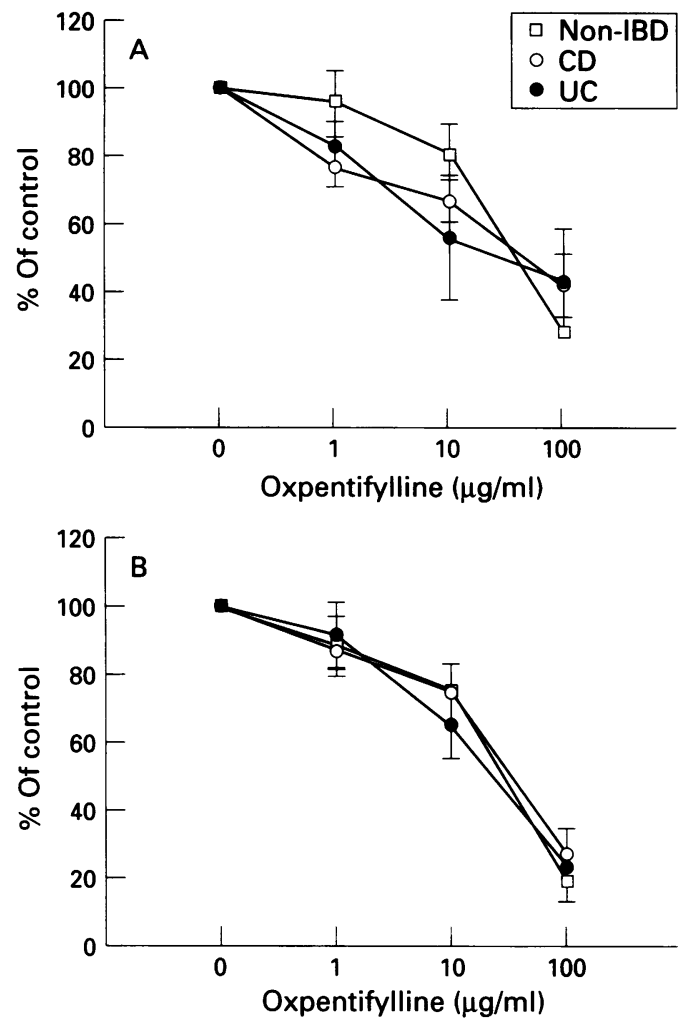

Figure 2: Comparison of the effect of PTX on TNF- $\alpha$ release by PBMCs isolated from healthy controls (noninflammatory bowel disease (non-IBD), $n=6$ ) and patients with Crohn's disease $(C D, n=10)$, or ulcerative colitis (UC, $n=4)$. The effect of PTX $(1,10$, and $100 \mu \mathrm{g} / \mathrm{ml})$ on cytokine production by PBMCs was evaluated by ELISA as described in Methods in the absence $(A)$ or presence $(B)$ of $1 \mu \mathrm{g} / \mathrm{ml} \mathrm{LPS}$ and $1 \mu \mathrm{g} / \mathrm{ml}$ PHA. Results (mean

(SEM)) express cytokine production as the percentage of control (100\% without LPS/PHA: non-inflammatory bowel disease, $698.2(114.7) \mathrm{pg} / \mathrm{ml}$, Crohn's disease, 736.5 (98.8) pg/ml, ulcerative colitis, $490 \cdot 3$ (93.9) pg/ml; $100 \%$ with LPS/PHA: non-inflammatory bowel disease, 891.6 (118.7) pg/ml, Crohn's disease, $1142 \cdot 8$ ( 232.5) pg/ml, ulcerative colitis, $1995 \cdot 9(164 \cdot 7) \mathrm{pg} / \mathrm{ml})$.

CYTOKINE CONCENTRATIONS IN THE ORGAN CULTURE SUPERNATANTS

Spontaneous cytokine production by intestinal biopsy specimens was not different in regard to disease activity (for example, $p<0.84$ for $\mathrm{TNF}-\alpha$ ), steroid treatment (for example,

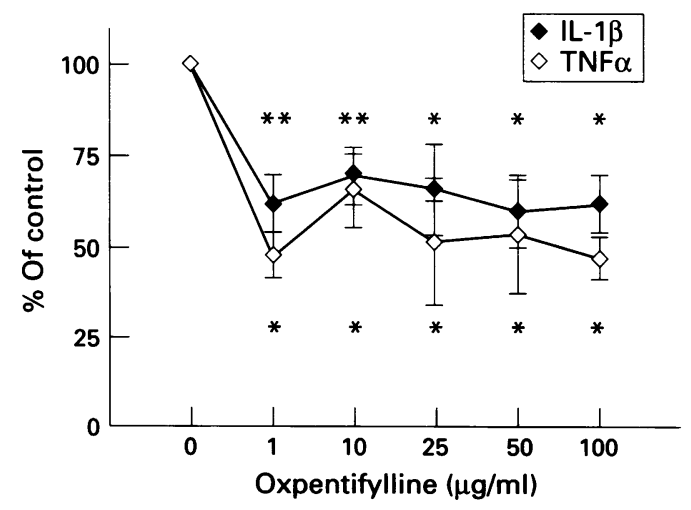

Figure 3: Effect of PTX on IL-1 $\beta$ and TNF- $\alpha$ concentrations in the supernatants of organ cultures of inflamed intestinal mucosa from patients with inflammatory bowel disease $(n=17)$. The effect of $P T X$ $(1,10,25,50$, and $100 \mu \mathrm{g} / \mathrm{ml})$ on cytokine production was evaluated by ELISA as described in Methods. Results (mean (SEM)) express cytokine production as the percentage of control (100\%: IL-1 $\mathrm{B}, 81.9$ (23.4) pg/ml; TNF $-\alpha, 75.2$ (19.9) $\left.\mathrm{pg} / \mathrm{ml} ;{ }^{*} p<0.001,{ }^{*}{ }_{p}<0.01\right)$. $\mathrm{p}<0.28$ for $\mathrm{TNF}-\alpha$ ), or mesalazine treatment (for example, $\mathrm{p}<0 \cdot 16$ for TNF- $\alpha$ ).

As found in PBMC cultures, PTX inhibited TNF- $\alpha$ release significantly in organ cultures of intestinal mucosa from patients with inflammatory bowel disease $\left(\mathrm{IC}_{50} \sim 25 \mu \mathrm{g} / \mathrm{ml}\right.$; $\mathrm{p}<0.0001$ ) (Fig 3). Concentrations of PTX exceeding $25 \mu \mathrm{g} / \mathrm{ml}$ were not able to enhance this inhibitory effect. No difference was seen between patients with Crohn's disease and those with ulcerative colitis $(p=0.33)$. The concentration of TNF- $\alpha$ inhibition by PTX was not influenced by disease activity $(p=0 \cdot 10)$, steroid $(p=0.57)$, or mesalazine $(p=0.59)$ treatment.

Concentrations of IL- $1 \beta$ were significantly decreased in the presence of PTX (about $40 \%$ of IL-1 $\beta$ released spontaneously; $p<0.0001$; Fig 3) by contrast with the effect in PBMC cultures. The effect of PTX was similar in patients with Crohn's disease and those with ulcerative colitis $(p=0.93)$.

Concentrations of IL-6 in the organ culture supernatants of inflamed mucosa from patients with inflammatory bowel disease increased significantly in the presence of PTX (144\% compared with spontaneous release; $\mathrm{p}<0.0025)$.

Concentrations of IL-8 were not modified in the presence of PTX $(p=0 \cdot 18)$.

\section{Discussion}

The present study shows the ability of PTX to inhibit (1) the release of TNF- $\alpha$ by PBMCs isolated from patients with inflammatory bowel disease and (2) the secretion of both TNF- $\alpha$ and IL-1 $\beta$ in the organ culture supernatants of inflamed intestinal mucosa from the same patients. The inhibition of TNF- $\alpha$ secretion by PBMCs from patients with inflammatory bowel disease was around $50 \%$ at a PTX concentration of $25 \mu \mathrm{g} / \mathrm{ml}\left(\mathrm{IC}_{50}\right)$, with similar potency in PBMCs from healthy controls. When PBMCs from patients with inflammatory bowel disease were activated by LPS/ PHA, the potency of PTX to inhibit TNF- $\alpha$ was further increased (up to $75 \%$ of control values) in accord with other reports. ${ }^{23}$ The inhibitory effect of PTX was similar in Crohn's disease or ulcerative colitis when checked in PBMCs or in organ cultures from patients with these diseases. This cytokine inhibiting effect did not differ between patients with active, moderate, or mild disease activity, and was not influenced by previous treatment with mesalazine or steroids. This finding may be partially explained because steroids and PTX probably inhibit TNF- $\alpha$ synthesis at distinct points in the signalling pathway; this has been suggested by Han et al, ${ }^{24}$ who showed in RAW 264.7 macrophages that PTX blocked TNF- $\alpha$ mRNA accumulation whereas dexamethasone strongly inhibited translational derepression, a mechanism not reported for PTX. These authors also showed that combined application of dexamethasone and PTX enhanced the inhibition of TNF- $\alpha$ synthesis compared with each drug alone.

Since inflammatory cytokines have been established as key mediators in the cascade of 
inflammatory events associated with inflammatory bowel disease, immunity modifying drugs have been developed, with some of them currently showing promising effects in animal models of experimental colitis or in humans with inflammatory bowel disease. This was, for example, shown by using IL-1ra in a rabbit model of formalin immune complex colitis, ${ }^{25}$ and by using chimeric antitumour necrosis factor monoclonal antibodies in active steroid refractory patients with Crohn's disease. ${ }^{11-13}$ Such treatments, although effective, are costly and not always well tolerated in humans. Furthermore, their efficacy and their safety in long term use remains to be established. ${ }^{13}$ The results, however, strongly suggest that inflammatory cytokines, in particular TNF- $\alpha$ and IL-1 $\beta$, are of major importance in the pathogenesis of inflammatory bowel disease, leading to the evaluation of other cytokine modulating molecules. Whether these drugs act exclusively through cytokine inhibition or involve multiple immune and inflammatory mechanisms remains to be determined. However, as cytokines appear as regulators at the initial steps of intestinal immune response, their inhibition may be a cornerstone in inflammatory bowel disease treatment.

Our results suggest that PDE inhibitors such as PTX may potentially be interesting in the field of cytokine inhibition in patients with Crohn's disease or ulcerative colitis. The difference between response in PBMCs, which was dose related, and the absence of a doseresponse effect in organ cultures remains to be explained. It may be related to the fact that organ cultures represent a complex system in which multiple cells interact. This difference may disappear using lamina propria mononuclear cells instead of organ cultures. Studies are currently in progress in our department to clarify this. Inhibition of IL-1 $\beta$ in organ cultures but not in PBMCs may also be the result of multiple cell-cell interactions in biopsy specimens. In fact, inhibition of IL-1 $\beta$ production by PBMCs - as well as down regulation of IL- 6 and IL- 8 release - by PTX has been reported in vivo under specific culture conditions, ${ }^{26}$ and described for IL-1 $\beta$ by Bienvenu et $a l^{27}$ using the whole blood model. Such data suggest that inhibiting TNF- $\alpha$ may result in the inhibition of IL-1 $\beta$, or cytokines with late expression such as IL-8.

As well as the role of TNF- $\alpha$ and IL- $1 \beta$ in the pathogenesis of inflammatory bowel disease, other cytokines seem to be potential targets in the treatment of Crohn's disease and ulcerative colitis. Previous studies have shown increased numbers of IL-2 and IFN- $\gamma$ secreting cells, especially in Crohn's disease. ${ }^{28}$ These studies have hypothesised that a Th1like profile of lymphokine production may exist in the mucosal lesions of Crohn's disease. Animal studies have indicated that the inhibitory properties of PTX are particular to Th1-like CD4+ $\mathrm{T}$ cells. ${ }^{29}{ }^{30}$ Furthermore, Novak and Rothenberg ${ }^{23}$ and Betz and Fox ${ }^{31}$ recently suggested that $\mathrm{Th} 1$ and $\mathrm{Th} 2$ cells could be distinguished by their ability to maintain a low cAMP concentration (Th1) and high cAMP concentration (Th2), respectively. Such a balanced effect may explain the increase in IL-6 in some of our experiments and also that reported for normal PBMCs. ${ }^{32}{ }^{33}$ The differential effect of PTX on TNF- $\alpha$ on the one hand and other cytokines on the other is currently not explained as the exact mechanisms of action of PTX are not known. One hypothesis was a selectivity in the induction of cytokine gene expression. Signals such as LPS, or effects of transcription factors on gene expression, vary largely from one gene to another. For TNF- $\alpha$, it is suspected that PTX modifies NF-KB activation or blocks the ras/ raf/MEK/MAPK pathway, ${ }^{34}{ }^{35}$ by enhancing intracellular cAMP concentrations. ${ }^{15} 3637$ By contrast, an increase in intracellular cAMP has been suggested to activate the IL- 6 gene. ${ }^{38}$

Various other immunological properties of PTX may be of interest regarding the current knowledge of immunopathogenesis of inflammatory bowel disease. This is the case for inhibition of tissue factor mRNA expression, ${ }^{39}{ }^{40}$ decrease in cytokine induced intercellular adhesion molecule- $1,{ }^{41}$ or reduction in fibroproliferation. ${ }^{42}$ Our data need to be extended further by in vitro and in vivo studies in humans and in animal models of inflammatory bowel disease before considering the question of therapeutic relevance of PTX or other PDE inhibitors in patients with inflammatory bowel disease. Since we began our work, ${ }^{43}$ open studies including a few patients with ulcerative colitis and Crohn's disease have been reported, with conflicting results. ${ }^{44} 45$ Treatment schedules usually used doses in the range of 1200-2400 mg/day which allowed the achievement of apparently adequate plasma concentrations of PTX, ${ }^{46}$ but showed no or only mild clinical results. Data on tissue concentrations are missing, but may explain contrasting results between in vivo studies and the present results.

In conclusion, our data show that PTX down regulates in vitro TNF- $\alpha$ and IL-1 $\beta$ production by PBMCs and intestinal organ cultures from patients with inflammatory bowel disease and indicate a potential interest in this drug and related compounds for treatment of Crohn's disease and ulcerative colitis.

This work was partially supported by a fellowship award to J-MR from FERRING Pharmaceutical Laboratories, Paris, France, and a grant from Association François AUPETIT
(sponsored by Solvay Pharma Laboratories), Paris, France. JSK (sponsored by Solvay Pharma Laboratories), Paris, France. JSK
was a visiting scientist from Antibody Solutions, Half Moon was a visiting scie
Bay, CA, USA.

1 Reimund JM, Duclos B, Sapin R, Derlon A, Chamouard P, Baumann R. Systemic tumour necrosis factor in Crohn's disease: relationship to disease activity and circulating acute phase reactants. Eur $\mathcal{F}$ Gastroenterol Hepatol 1992; 4: 919-23.

2 Braegger CP, Nicholls S, Murch SH, Stephens S, MacDonald TT. Tumour necrosis factor alpha in stool as a marker of intestinal inflammation. Lancet 1992; 339: 89-91.

3 Mazlam MZ, Hodgson HJF. Peripheral blood monocyte cytokine production and acute phase response in inflammatory bowel disease. Gut 1992; 33: 773-8.

4 Reinecker HC, Steffen M, Witthoeft T, Pflueger I, Schreiber S, MacDermott RP, et al. Enhanced secretion of tumor necrosis factor-alpha, IL- 6 , and IL- $1 \beta$ by of tumor necrosis factor-alpha, IL-6, and IL-1 $\beta$ by isolated lamina propria mononuclear cells from patients with ulcerative colitis and

5 Reimund JM, Wittersheim C, Dumont S, Muller CD, Baumann R, Poindron P, Duclos B. Mucosal inflammatory cytokine production by intestinal biopsies in patients 
with ulcerative colitis and Crohn's disease. $\mathcal{F}$ Clin Immunol 1996; 16: 144-50.

6 Reimund JM, Wittersheim C, Dumont S, Muller CD Kenney JS, Baumann R, Poindron P, Duclos B. Increased production of tumour necrosis factor-alpha, IL- $1 \beta$ and IL- 6 by morphologically normal intestinal biopsies in Crohn's disease. Gut 1996; 39: 684-9.

7 Sher ME, D'Angelo AJ, Stein TA, Bailey B, Burns G. Cytokines in Crohn's colitis. Am f Surg 1995; 169: 133-6

8 Mazlam MZ, Montazeri G, Hodgson HJF. The effects of some anti-inflammatory agents on cytokine release from human monocytes in vitro. Eur $\mathcal{f}$ Gastroenterol Hepatol 1993; 5: 515-20

9 Mitsuyama K, Sasaki E, Toyonaga A, Ikeda H, Tsuruta O, Irie A, et al. Colonic mucosal interleukin-6 in inflammatory bowel disease. Digestion 1991; 50: 104-11.

10 Mitsuyama K, Tovonaga A, SasakiE, Watanabe K, TateishiH, Nishiyama T, et al. IL-8 as an important chemoattractant for neutrophils in ulcerative colitis and Crohn's disease. Clin Exp Immunol 1994; 96: 432-6.

11 Derkx B, Taminiau J, Radema S, Stronkhorst A, Wortel C, Tytgat GNJ, et al. Tumour-necrosis-factor antibody treatment in Crohn's disease. Lancet 1993; 342: 173-4.

12 Van Dullemen HM, Van Deventer SJH, Hommes DW, Bijl HA, Jansen J, Tytgat GNJ, et al. Treatment of Crohn's Bijl HA, Jansen J, Tytgat GNJ, et al. Treatment of Crohn's
disease with anti-tumor necrosis factor chimeric monoclonal antibody (cA2). Gastroenterology 1995; 109: 129-35

13 Targan S, Rutgeerts P, Hanauer SB, Van Deventer HJS, Mayer L, Present $\mathrm{DH}$, et al. A multicenter trial of antitumor necrosis factor (TNF) antibody (cA2) for treatment of patients with active Crohn's disease [abstract]. Gastroenterology 1996; 110: A1026.

14 Henderson B, Blake S. Therapeutic potential of cytokine manipulation Trends Pharmacol $S_{c i}$ 1992; 13: 145-52.

15 Bessler H, Gilgal R, Dialdetti M, Zahavi I. Effects of pentoxifylline on the phagocytic activity, cAMP levels, and superoxide anion production by monocytes and polymorphonuclear cells. I Leukocyte Biol 1986; 40: $747-57$

16 Tannenbaum CS, Hamilton TA. Lipopolysaccharideinduced gene expression in murine peritoneal macrophages is selectively suppressed by agents that elevate intracellular cAMP. F Immunol 1989; 142: 1274-80.

17 Lennard-Jones JE. Definition and diagnosis in regional enteritis. Skandia International Symposium Nordiska. Stockholm: SISN, 1971: 105-116.

18 Van Hees PAM, Van Elteren PH, Van Lier HJJ, Van Tongeren JHM. An index of inflammatory activity in patients with Crohn's disease. Gut 1980; 21: 279-86.

19 Truelove SC, Witts LJ. Cortisone in ulcerative colitis. Final report on a therapeutic trial. $B M 7$ 1955; ii: $1041-8$.

20 Bøyum A. Isolation of mononuclear cells and granulocytes from human blood. Scand $\mathcal{F}$ Lab Invest 1968; 21 : 77-89.

21 Wardle TD, Hall L, Turnberg LA. Use of coculture of colonic mucosal biopsies to investigate the release of eicosanoids by inflamed and uninflamed mucosa from patients with inflammatory bowel disease. Gut 1992; 33: 1644-5

22 Kenney JS, Masada MP, Eugui EM, Delustro BM, Mulkins MA, Allison AC. Monoclonal antibodies to human recombinant interleukin 1 (IL1) $\beta$ : quantification of IL1 $\beta$ and inhibition of biological activity. $\mathcal{F}$ Immunol 1987; 138: 4236-42

23 Novak KJ, Rothenberg EV. cAMP inhibits induction of interleukin 2 but not of interleukin 4 in T cells. Proc Nat interleukin 2 but not of interleuki
Acad Sci USA 1990; 87: 9353-7.

24 Han J, Thompson P, Beutler B. Dexamethasone and pentoxifylline inhibit endotoxin-induced cachectin/tumor necrosis factor synthesis at separate points in signaling pathway. $\mathcal{F}$ Exp Med 1990; 172: 391-4.

25 Cominelli F, Nast CC, Duchini A, Lee M. Recombinant interleukin-1 receptor antagonist blocks the proinflammatory activity of endogenous interleukin-1 in rabbit immune colitis. Gastroenterology 1992; 103: 65-71.

26 Neuner P, Klosner G, SchauerE, Pourmojib M, MacheinerW, Grünwald $\mathrm{C}$, et al. Pentoxifylline in vivo down-regulates the release of IL- $1 \beta$, IL- 6 , IL- 8 and tumor necrosis factor- $\alpha$ by human peripheral blood mononuclear cells. factor- $\alpha$ by human periphera.

27 Bienvenu J, Doche C, Gutowski M-C, Lenoble M, Lepape A, Perdrix J-P. Production of proinflammatory cytokines and cytokines involved in the $\mathrm{TH} 1 / \mathrm{TH} 2$ balance is modulated by pentoxifylline. 7 Cardiovasc Pharmacol 1995; 25 (supp 2): $S 80-4$

28 Breese E, Braegger CP, Corrigan CJ, Walker-Smith JA, MacDonald TT. Interleukin-2 and interferon gamma secreting cells in normal and diseased human intestinal mucosa. Immunologv 1993; 78: 127-31.

29 Rott O, Cash E, Fleischer B. Phosphodiesterase inhibitor pentoxifylline, a selective suppressor of T helper type 1but not type 2 -associated lymphokine production, pre-
vents induction of experimental autoimmune encephalovents induction of experimental autoimmune encephalo-
myelitis in Lewis rats. Eur f Immunol 1993; 23: 1745-51.

30 Thanhaüser A, Reiling N, Böhle A, Toellner K-M, Duchrow M, Scheel D, et al. Pentoxifylline: a poten inhibitor of IL- 2 and IFN- $\gamma$ biosynthesis and BCGinduced cytotoxicity. Immunology 1993; 80: 151-6.

31 Betz M, Fox BS. Prostaglandin $\mathrm{E}_{2}$ inhibits production of Th1 lymphokines but not of Th2 lymphokines. 7 Immunol 1991; 146: 108-13.

32 Waage A, Sorensen M, Stordal B. Differential effect of oxpentifylline on tumour necrosis factor and interleukin- 6 production. Lancet 1990; 335: 543

33 Schandené L, Vandenbussche P, Crusiaux A, Alègre ML Abramowicz D, Dupont E, et al. Differential effects of pentoxifylline on the production of tumor necrosis factoralpha (TNF- $\alpha$ ) and interleukin-6 (IL-6) by monocyte and T cells. Immunology 1992; 76: 30-4

34 Beutler B, Kruys V. Lipopolysaccharide signal transduction regulation of tumor necrosis factor biosynthesis, and signaling by tumor necrosis factor itself. 7 Cardioras Pharmacol 1995; 25 (suppl 2): S1-8.

35 Hakim J. Pharmacologic control of intracellular signaling pathways: from research to therapy. $f$ Cardiovasc Pharmacol 1995; 25 (suppl 2): S106-13.

36 Endres S, Fülle H-J, Sinha B, Stoll D, Dinarello CA, Gerzer R, et al. Cyclic nucleotides differentially regulate the synthesis of tumour necrosis factor $\alpha$ and interleukin- $1 \beta$ by thesis of tumour necrosis factor- $\alpha$ and interleukin-1 $\beta$ by

37 Strieter RM, Remick DG, Ward PA, Spengler RN, Lynch JP, Larrick J, et al. Cellular and molecular regulation of the tumor necrosis factor-alpha production by pentoxifylline. Biochem Biophys Res Commun 1988; 155 1230-6.

38 Zhang Y, Lin JX, Vilcek J. Synthesis of interleukin 6 interferon- $\beta_{2} / \mathrm{B}$ cell stimulatory factor 2 ) in human fibroblasts is triggered by an increase in intracellular cyclic AMP. F Biol Chem 1988; 263: 6177-82.

39 Ollivier V, Ternisien C, Vu T, Hakim J, De Prost D. Pentoxifylline inhibits the expression of tissue factor mRNA in endotoxin-activated human monocytes. FEBS Lett 1993; 322: 231-4.

40 Ramani M, Khechai F, Ollivier V, Ternisien C, Bridey F, Hakim D, et al. Interleukin-10 and pentoxifylline inhibi $\mathrm{C}$-reactive protein-induced tissue factor gene expression in peripheral human blood monocytes. FEBS Lett 1994 356: $86-8$

41 De Fraissinette A, Berman B, Duncan MR, Lefevre I Effects of pentoxifylline on interferon-gamma (IFN- $\gamma$ ) and tumor necrosis factor-alpha (TNF- $\alpha$ ) induction of intercellular adhesion molecule-1 (ICAM-1) expression on human keratinocytes and Langerhans cells. Eur $\mathcal{F}$ Dermatol 1992; 2: 266-72

42 Peterson TC, Isbrucker RA, Hooper ML. In vitro effects of platelet-derived growth factor on fibroproliferation and effect of cytokine antagonists. Immunopharmacologv 1994; 28: $259-70$.

43 Reimund JM, Muller Ch, Dumont S, Allison AC, Baumann $\mathrm{R}$, Poindron $\mathrm{Ph}$, et al. Comparaison de l'effe in vitro de certains anti-oxydants et de la pentoxifylline (POF) sur la sécrétion de cytokines au cours des maladies inflammatoires chroniques de l'intestin (MICI) [abstract]. Gastroenterol Clin Biol 1995; 19: A36.

44 Kam I, Casini-Raggi V, Cominelli F. Pentoxifylline: a novel treatment for ulcerative colitis [abstract]. Gastroenterology 1995; 108: A845.

45 Bauditz J, Rückert Y, Raedler A, Nikolaus S, Lochs H, Schreiber S. Tumour necrosis factor inhibition by oxpentifylline and intestinal inflammation in Crohn's disease. Lancet 1995; 345: 1445.

46 DeVault GA, Kohan DE, Nelson EW, Holman JM. The effects of oral pentoxifylline on the cytokine release syndrome during inductive OKT3. Transplantation 1994 57: 532-40. 